\title{
Consciência e auto relação na primeira filosofia de Sartre: um exame a partir de um debate contemporâneo sobre a consciência
}

\author{
Tárik de Athayde Prata*
}

DOI 10.20399/P1982-999X.2016v1n2pp76-93

\begin{abstract}
Resumo
O artigo examina a concepção de consciência articulada por Sartre em seus primeiros escritos filosóficos, na tentativa de elucidar a característica da consciência segundo a qual todo episódio particular de consciência é consciência de si mesmo. Após uma discussão dos conceitos de consciência irrefletida e consciência reflexiva de Sartre, são discutidas as concepções de consciência de David Rosenthal e Rocco Gennaro, que defendem variações da teoria da consciência como monitoramento de segunda ordem. A tese defendida no presente artigo é que a auto relação da consciência na teoria de Sartre pode ser compreendida como parte de uma totalidade complexa, que pode ser conceitualmente analisada.
\end{abstract}

Palavras-chave: Sartre; Consciência; Auto-relação; Monitoramento de segunda ordem.

\begin{abstract}
The paper investigates Sartre's view about consciousness, expressed in his early philosophical writings, aiming to clarify the property of all token conscious episodes to be selfconsciousness. After a discussion of Sartre's concepts of irreflective and reflexive consciousness, the views of David Rosenthal and Rocco Gennaro about consciousness are discussed. These authors advocate variations of the theory of consciousness as higher order monitoring. The thesis defended in the present paper is that the selfrelation of consciousness in Sartre's theory can be understood as a part of a complex whole, that can be conceptually analised.
\end{abstract}

Key-words: Sartre; Consciousness; Selfrelation; Higher order monitoring.

Jean-Paul Sartre (1905-1980) foi, sem dúvida nenhuma, um dos mais importantes intelectuais do século XX - filósofo, romancista, militante político, teatrólogo, roteirista ${ }^{1}$ - e entre suas inúmeras contribuições ao pensamento está uma interessante reflexão acerca dos fundamentos filosóficos da psicologia, reflexão esta que foi motivada por seu interesse visceral pela literatura.

Criado no ambiente bastante intelectualizado da casa de seu avô, Charles Schweitzer ${ }^{2}$, Sartre se acostumou desde a infância a uma vida reflexiva, impulsionada pela leitura ${ }^{3}$, e desde muito cedo alimentou o ideal de se dedicar ao fazer literário. Anos depois, por volta de 1922, durante o curso preparatório para a seleção da École Normale Superieure, uma das mais respeitadas instituições acadêmicas da França, ele tomou

*Graduado em Psicologia e Mestre em Filosofia Contemporânea pela Universidade Federal do Ceará (UFC). Doutor em Filosofia pela Ruprecht-Karl Universität Heidelberg (Alemanha). Professor Adjunto do Departamento de Filosofia da Universidade Federal de Pernambuco (UFPE). Desenvolve pesquisas nas áreas de Filosofia da Mente e Filosofia da Psicologia.

1 Sartre "abordou todos os domínios da escrita (romance, novela, filosofia, teatro, cinema, biografia, autobiografia, ensaio crítico, reportagem jornalística, canção, entre outros)" (COHEN-SOLAL, 2007, p. 16).

2 “Comecei minha vida como hei de acabá-la, sem dúvida: no meio dos livros. No escritório de meu avô, havia-os por toda parte; era proibido espaná-los exceto uma vez por ano antes do reinício das aulas em outubro. Eu ainda não sabia ler e já reverenciava essas pedras erigidas: em pé ou inclinadas, apertadas como tijolos nas prateleiras da biblioteca ou nobremente espacejadas em aléias de menires, eu sentia que a prosperidade da nossa família delas dependia. Elas se pareciam todas; eu foliava num minúsculo santuário, circundado de monumentos atarracados, antigos, que me haviam visto nascer, que me veriam morrer e cuja permanência me garantia um futuro tão calmo quanto o passado" (SARTRE, 1967, p. 27).

3 "A leitura teve um papel muito importante desde minha infância. Eu me refugiava nas palavras, nos livros" (Sartre por ele mesmo; 20m 41s). Estes números indicam, respectivamente, o minuto e o segundo em que se inicia a passagem citada do filme de Alexandre Astruc e Michel Contat. 
contato com uma influência decisiva: nas aulas de filosofia, deparou-se com a leitura de Os dados imediatos da consciência, de Henri Bergson, obra que despertou em Sartre a vocação filosófica. De acordo com a grande biógrafa de Sartre, Annie Cohen-Solal (1986, p. 90):

A partir da leitura decisiva, Sartre se torna um filósofo por fervor e necessidade, compreendendo que tem nas mãos um instrumento muito mais poderoso, muito mais útil do que qualquer outra revelação anterior. Daí por diante confere, ao que chama de filosofia, uma condição de extrema onipotência.

Tal "onipotência" diz respeito à abrangência totalizante que Sartre atribuía à filosofia. Nesses primeiros contatos, ela pareceu a Sartre ser "o conhecimento do mundo" 4 , que, portanto, forneceria ao escritor o alicerce indispensável para poder falar de tudo o que nos cerca: "Um escritor tinha de ser um filósofo. A partir do momento em que soube o que era a filosofia, parecia-me normal exigir isso de um escritor" (BEAUVOIR; SARTRE, 1982, p. 191). ${ }^{5}$

E foi, justamente, essa empreitada filosófica, guiada pela literatura, que conduziu Sartre a reflexões acerca da psicologia. De acordo com Cohen-Solal, para ele a filosofia seria uma "colaboradora ideal, uma vez que autorizava o acesso simultâneo a dois campos de interesse privilegiados: a vida psíquica do escritor em perspectiva; o mundo fictício que iria criar" (1986, p. 90). Desse modo, a reflexão filosófica "seria, de certa maneira, uma introdução à psicologia e à criação romanesca" (Ibidem, p. 104). É por isso que, nesses primeiros anos, de acordo com o próprio Sartre, "o que eu chamava de 'filosofia' era pura e simplesmente psicologia" (Ibidem, p. 90). ${ }^{6}$ Essa visão a respeito do saber filosófico transparece claramente nos primeiros escritos filosóficos de Sartre: $A$ imaginação (1936), A transcendência do ego (1937), Esboço de uma teoria das emoções (1939), Uma ideia fundamental da fenomenologia de Husserl: a intencionalidade (1939) e $O$ imaginário (1940), - todos eles anteriores ao clássico $O$ ser e o nada (1943) - escritos que foram produzidos sob uma importante influência: o pensamento fenomenológico de Edmund Husserl (1859-1938), pensamento que Sartre conheceu por volta de $1933 .^{7}$

Dentro dessa sua abordagem filosófica da psicologia, Sartre teve de se ocupar detidamente com a noção de consciência, central para o saber psicológico. Não se pode perder de vista que, na verdade, a palavra "consciência" é extremamente ambígua, podendo ser empregada para expressar conceitos extremamente distintos entre si (cf.

\footnotetext{
4 "Havia todas as ciências que pertenciam à filosofia; em metodologia, aprendia-se como se constitui uma ciência. E, para mim, do momento em que se sabia como se faz matemática, ou as ciências naturais, isso significava que se conheciam todas as ciências naturais e matemáticas; portanto, eu pensava que se me especializasse em filosofia apreenderia o mundo inteiro, sobre o qual deveria falar em literatura. Isso me dava, digamos, a matéria" (BEAUVOIR; SARTRE, 1982, 189-90).

5 "A filosofia sempre será para ele um meio de acesso, um utensílio privilegiado para o romance" (COHEN-SOLAL, 1986, p. 105).

${ }^{6}$ Trata-se aqui de uma declaração de Sartre em entrevista citada por Cohen-Solal.

7 "Raymond Aron passava o ano no instituto francês de Berlim e, enquanto preparava uma tese sobre história, estudava Husserl. Quando veio a Paris, falou com Sartre. Passamos uma noite juntos no Bec de Graz, na rua Montparnasse; pedimos a especialidade da casa: coquetéis de abricó. Aron apontou seu copo: 'Estás vendo, meu camaradinha, se tu és fenomenologista, podes falar deste coquetel, e é filosofia'. Sartre empalideceu de emoção, ou quase; era exatamente o que ambicionava há anos: falar das coisas tais como a tocava, e que fosse filosofia. Aron convenceu-o de que a fenomenologia atendia exatamente a suas preocupações: ultrapassar a oposição do idealismo e do realismo, afirmar a um tempo a soberania da consciência e a presença do mundo, tal como se dá a nós" (BEAUVOIR, 1984, p. 138). (Cf. ainda: COHEN-SOLAL, 1986, p. 136-7; THODY, 1974, p. 40).
} 
BIERI, 1996; GÜZELDERE, 1997). A diversidade de possíveis sentidos de "consciência" já foi há muito tempo reconhecida na tradição fenomenológica (cf. HUSSERL, 1984a, p. 356 [295]) ${ }^{8}$, assim como por seus precursores (cf. BRENTANO, 1924, p. 141 [101]). No início do seu livro O imaginário: psicologia fenomenológica da imaginação, Sartre esclarece que usará “o termo 'consciência' não para designar a mônada e o conjunto de suas estruturas psíquicas, mas para nomear cada uma dessas estruturas em sua particularidade concreta." (SARTRE, 1996, p. 13). Está assim sugerida uma diferença entre (A) a consciência enquanto um todo de estruturas mentais e (B) enquanto cada uma dessas estruturas particulares (como uma imagem mental, uma percepção, um conceito, etc.). Nos textos de Sartre que discutiremos a seguir, o uso da palavra "consciência" é sempre o que se refere a cada estrutura particular, e é importante perceber que cada consciência reflexiva, assim como cada consciência irrefletida, é um episódio particular de consciência (é uma "consciência" no segundo sentido da citação acima). ${ }^{9}$

Sob a influencia de Husserl (e de Bergson), a concepção de Sartre sobre a consciência rompe com a visão de que a consciência é algo análogo a um espaço. Para ele, a consciência não é uma coisa, não é um lugar (como pode nos fazer pensar nosso hábito de pensar em termos da realidade física, o espaço e os objetos), a consciência é uma atividade, uma vasta série de manifestações, de diferentes aspectos, uma atividade que se dirige para as coisas do mundo de diferentes maneiras.

Dizer que a consciência "se dirige" para as coisas do mundo nos traz para uma primeira característica da consciência, que é essencial na visão de Sartre: a intencionalidade. Seguindo a perspectiva de Husserl, Sartre afirma que: "Toda consciência, (...), é consciência de alguma coisa" (SARTRE, 1943, p. 17 [22]), o que significa que não há nenhuma consciência que não seja posicionamento de um objeto transcendente (pondo este objeto, por exemplo, como existente, como ausente, como existente em outro lugar, etc. - cf. SARTRE, 1996, pp. 26-28). Essa primeira característica diz respeito à "necessidade para a consciência de existir como consciência de outra coisa que ela" (SARTRE, 2005, p. 106), uma relação da consciência a seus objetos, relação que pode se dar de diferentes maneiras. ${ }^{10}$

A noção de intencionalidade evidencia que a consciência, na perspectiva de Sartre, não é um espaço misterioso, onde habitam simulacros das coisas exteriores. A consciência é, simplesmente, um movimento para fora de si (intendere) ${ }^{11}$, um

\footnotetext{
${ }^{8} \mathrm{O}$ primeiro número de página é da edição na língua original, enquanto o número entre colchetes é da página da tradução consultada para a redação do presente artigo.

${ }^{9}$ Nesse sentido, é importante perceber que esse uso sartreano do termo "consciência", não coincide com o uso de autores mais recentes, como Rosenthal e Gennaro, já que para estes a palavra "consciência" designa uma certa característica de estados mentais, característica que pode faltar a estes estados. Em outras palavras, defensores da concepção de consciência como monitoramento de segunda ordem aceitam a existência de fenômenos mentais inconscientes, o que já não é tão simples para Sartre (Cf. GENNARO, 2002, p. 299-301).

${ }^{10}$ Um ser consciente é capaz de pensar sobre algo, fixando seu conceito (p. ex., o conceito de terremoto), pode imaginá-lo (p. ex., imaginar os prédios e as casas do seu bairro tremendo com o abalo sísmico), pode também temê-lo (p. ex., temer que um terremoto destrua a sua casa), odiá-lo (p. ex., depois que isso tivesse acontecido), ou desejá-lo (p. ex., para ter, com a destruição, um pretexto para abandonar uma situação, um lugar). Um extenso, incontável, conjunto de modos psicológicos como esses é o que constitui a consciência enquanto intencionalidade.

11 "O adjetivo 'intencional' e o substantivo abstrato 'intencionalidade', derivado daquele, foram cunhados pelos filósofos medievais ou escolásticos. A expressão se deriva do latim intendere que significa 'visar', no sentido de esticar o arco afim de disparar uma flecha em um alvo (intendere ad arcum). Os termos 'intencional' e 'intencionalmente', comumente utilizados para descrever ações, derivam-se da mesma origem, e retém o sentido de um objetivo ou alvo ao qual a ação é visada” (MASLIN, 2009, p. 23).
} 
movimento em direção às coisas, pois ela é acerca das coisas do mundo, de tal modo que não há uma barreira entre interioridade e exterioridade para ser superada. Nas palavras de Sartre (2005, p. 106):

A consciência é pura, ela é clara como um grande vento, não há nada nela, salvo um movimento para fugir de si, um deslizamento para fora de si; se, pela impossibilidade, vós entrares "numa" consciência, vós seríeis agarrado por um turbilhão e rejeitado para fora, perto da árvore, na plena poeira, pois a consciência não tem "dentro"; ela não é nada senão o fora dela mesma e é essa recusa absoluta, essa recusa de ser substância que a constitui como consciência.

Mas há uma segunda característica da consciência que, na visão de Sartre, é ainda mais fundamental: trata-se da característica de toda consciência de ser sempre consciência de si, ao mesmo tempo em que é consciência (intencional) de um objeto transcendente. Sartre afirma que toda consciência de algo é consciência de si "na exata medida em que é consciência de um objeto transcendente" (SARTRE, 1966, p. 24 [188], grifado no original), e o problema central do presente trabalho é que Sartre parece pensar essa auto relação da consciência como algo primitivo, no sentido de não ser passível de análise. Ele afirma que o modo de existência da consciência, simplesmente, é ser autoconsciência (cf. SARTRE, 1966, p. 24 [188]), e afirma que essa auto relação é "a lei de sua existência" (Ibidem, p. 24 [188]), sugerindo que ela não pode ser explicada. $\mathrm{Na}$ introdução de $O$ ser e o nada, o filósofo chega a comparar a auto relação da consciência com as dimensões inerentes à espacialidade de um objeto físico, ou seja: assim como um objeto físico é espacial, existindo, portanto, nas três dimensões, do mesmo modo a consciência é autoconsciência (cf. SARTRE, 1943, p. 20 [25]).

Entretanto, esta (pelo menos aparente) renúncia a uma análise conceitual da auto relação da consciência não me parece desejável, pois essa renúncia introduziria no conceito de consciência (tão rico e interessante) articulado por Sartre um núcleo de obscuridade. Se não podemos conceber conceitualmente a auto relação, se temos, simplesmente, que aceitar que toda consciência é consciência de si, parece que nossa capacidade de compreensão não alcança, justamente, o aspecto mais importante da consciência (na visão de Sartre).

No presente artigo, propõe-se uma reflexão sobre a noção sartreana da consciência a partir da perspectiva de Rocco Gennaro, autor de destaque no debate contemporâneo sobre a consciência na filosofia da mente ${ }^{12}$, que elaborou uma interpretação do conceito de Sartre à luz de sua própria teoria da consciência, chamada por ele de "Perspectiva da intrinsicalidade ampla" (Wide Intrisicality View). Gennaro declara compartilhar com Sartre a visão de que a consciência implica autoconsciência, e acredita que a concepção do filósofo francês pode se tornar mais clara (do ponto de vista da filosofia analítica) se for comparada com a sua teoria (cf. GENNARO, 2002, p. 393-94).

Fundamentalmente, a tese defendida no presente trabalho é a de que a visão de Sartre sobre a consciência pode ser interpretada como uma visão na qual cada episódio de consciência (cada percepção, cada imagem mental, cada sentimento) é concebido enquanto uma totalidade sintética. Em outras palavras, cada episódio de consciência seria formado por elementos cuja efetiva articulação (síntese) é indispensável para a efetiva existência da consciência (em sua forma fundamental - irrefletida). Essa tese

\footnotetext{
${ }^{12}$ A respeito da filosofia da mente enquanto uma área de estudos na tradição da filosofia analítica, Cf. HEIL, 2001; CHURCHLAND, 2004; COSTA, 2005; MASLIN, 2009.
} 
será defendida com base em discussões mais recentes sobre a consciência, pois existem teorias sobre a consciência na filosofia da mente (articuladas por pensadores como David Rosenthal e o próprio Gennaro) que se mostram bastante esclarecedoras para a concepção de Sartre a respeito da consciência.

O trabalho seguirá o seguinte percurso: primeiramente, serão discutidas as noções de consciência reflexiva e consciência irrefletida de Sartre, tomando como exemplo ilustrativo o caso da imagem mental, evidenciando que, ao mesmo tempo em que Sartre sugere a relação da consciência consigo mesma enquanto um primitivo (não passível de análise conceitual), ele também sugere que a consciência irrefletida possui complexidade interna (seção 1). Em seguida, serão discutidas duas concepções contemporâneas a respeito da consciência como uma propriedade de estados mentais: a "teoria H.O.T." de Rosenthal e a "Perspectiva da intrinsicalidade ampla" de Gennaro, concepções que ajudam a construir uma interpretação esclarecedora da teoria de Sartre (seção 2). Por fim, a visão de Sartre sobre a consciência será interpretada à luz da teoria de Gennaro, na tentativa de mostrar que a consciência pode ser entendida como uma totalidade complexa (seção 3).

\section{Reflexão e consciência irrefletida}

De acordo com Sartre, toda consciência irrefletida de algo (a percepção de um objeto físico, a imagem mental de um amigo que se encontra em um lugar distante, etc.) é consciência posicional de seu objeto, ao mesmo tempo em que é autoconsciência não posicional. No que diz respeito a esta autoconsciência, seu caráter não posicional significa que não há cisão entre uma apreensão e o seu objeto, há apenas uma auto apreensão imediata (Cf. SARTRE, 1966, p. 23-24 [188-89]). Já no caso da consciência reflexiva, não temos uma única manifestação de consciência que se relaciona consigo mesma, temos duas manifestações distintas, onde uma faz a outra de objeto: por um lado, uma manifestação de consciência que Sartre designa como reflexionante, (nela mesma irrefletida $)^{13}$, por outro lado uma manifestação de consciência que ele denomina refletida (cf. Ibidem, p. 28 [191]).

Para elucidar a diferença entre a reflexão e a consciência irrefletida, será discutido o exemplo das imagens mentais, que é apenas um exemplo possível, entre as diversas formas de consciência, mas é um exemplo que foi discutido com mais detalhes por Sartre em algumas de suas principais obras (cf. SARTRE, 1978; Sartre, 1996). Conforme exposto anteriormente, foi o visceral impulso de Sartre para a carreira literária que o levou à filosofia e a articular uma psicologia filosófica da imaginação. A imagem mental, ou "consciência imaginante de algo" (cf. SARTRE, 1996, p. 19) era para ele um dos diversos modos como a consciência se manifesta e, em seu trabalho filosófico sobre ela, ele submete a imagem ao exame da reflexão na tentativa de obter conhecimentos certos a seu respeito. O emprego da reflexão como método específico da investigação filosófica já indica a importância da distinção operada por Sartre entre a consciência irrefletida, por um lado, e a consciência reflexiva, por outro.

Uma coisa é imaginar como está, agora, um amigo que se encontra em um lugar distante, e ter esse amigo como objeto de tal consciência em imagem. Outra coisa, bastante diferente, é deslocar minha atenção do objeto da imagem (nesse caso, o amigo) em direção à própria imagem enquanto tal, isto é, enquanto modo da consciência. No

\footnotetext{
${ }^{13}$ Uma consciência reflexionante (que se volta sobre outra manifestação de consciência), é ela própria irrefletida, e como toda consciência irrefletida, a consciência reflexionante também é autoconsciente de modo não-posicional, ou seja, também a consciência reflexionante é consciência de ser consciência de algo.
} 
primeiro caso tenho a consciência completamente voltada para o seu objeto (e completamente esquecida de si mesma). Já no segundo caso, tenho uma manifestação de consciência (a atenção reflexiva) voltada para outra manifestação de consciência (a imagem inicial). ${ }^{14}$

\section{CONSCIÊNCIA IRREFLETIDA}

\section{CONSCIÊNCIA REFLEXIVA}

\author{
Consciência \\ reflexionante
}

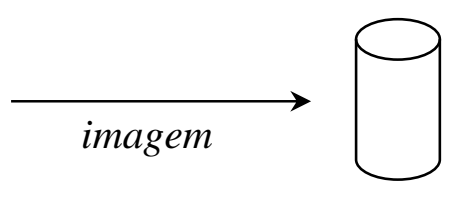

(objeto)

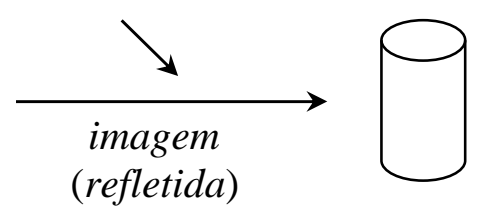

(objeto)

A consciência, no modo irrefletido, volta-se completamente para o objeto transcendente ${ }^{15}$, e possui uma série de características, que só podem ser tema de um discurso articulado quando outra manifestação de consciência se volta sobre ela, operando a reflexão. Na construção de sua teoria da imaginação, Sartre utiliza como método "produzir (...) imagens, refletir sobre essas imagens, descrevê-las, isto é, tentar determinar e classificar seus traços distintivos." (SARTRE, 1996, p. 16).

Mas consideremos agora a consciência em sua forma fundamental de manifestação, a consciência irrefletida, quando não há uma consciência reflexionante tomando-a como objeto. Nessa forma irrefletida, a consciência é consciência de si mesma, é relacionada a si mesma, e a maneira como um episódio de consciência se relaciona a si mesmo pode ser ilustrada através da diferença entre dois modos de consciência como a imagem e a percepção.

É importante notar que, em sua teoria da imagem, Sartre diverge radicalmente da tradição que a concebe como algo análogo à percepção. Para ele, imagem e percepção são manifestações de consciência completamente distintas (e a diferença entre elas reside entre outras coisas, no modo como cada uma se auto apreende). Na consciência perceptiva há uma passividade característica, que se mostra no fato de essa consciência pôr o seu objeto como real, como independente dela. Em outras palavras, a percepção põe seu objeto como algo transcendente, isto é, existente para além da consciência que se tem dele, o que faz do objeto da percepção algo que é posto pela consciência como inesgotável: "a cada instante, há sempre infinitamente mais do que o que podemos ver; para esgotar a riqueza de minha percepção atual, seria necessário um tempo infinito.

\footnotetext{
14 “Assim, a imagem enquanto imagem só é descritível por um ato de segundo grau, com o que o olhar se desvia do objeto para dirigir-se sobre a maneira como o objeto é dado. É o ato reflexivo que permite o julgamento 'eu tenho uma imagem'." (SARTRE, 1996, p. 15).

15 Apesar de a consciência irrefletida permanecer totalmente voltada para o seu objeto, isso não significa que ela não apreenda a si mesma de forma alguma. Para Sartre, se a consciência fosse uma simples relação ao objeto transcendente, isso significaria que ela é uma consciência inconsciente, o que é um absurdo (cf. SARTRE, 1943, p. 18 [23]). A consciência irrefletida é relação com o objeto, mas é, ao mesmo tempo, relação consigo mesma: ela apreende o objeto e, também, apreende a si mesma, embora ela se apreenda de uma forma diferente daquela em que ela apreende o seu objeto. Para entender isso, é importante considerar a diferença entre consciência posicional e não posicional, que será discutida a seguir.
} 
Que não nos enganemos: essa maneira de 'exceder' é constitutiva da própria natureza dos objetos." (SARTRE, 1996, p. 22). E à transcendência do objeto corresponde um caráter passivo (que a consciência perceptiva capta implicitamente, na exata medida em que apreende o objeto), pois a percepção apenas acolhe um objeto que existe independentemente da consciência que se possa ter dele.

Já no caso da imagem, o objeto imaginado não é posto por essa consciência como algo inesgotável, pois "na imagem há sempre uma espécie de pobreza essencial (...). Os diferentes elementos de uma imagem não mantém nenhuma relação com o resto do mundo e só mantém entre si umas duas ou três relações" (SARTRE, 1996, p. 22). A essa "pobreza" com a qual a imagem coloca seu objeto corresponde, na visão de Sartre, a auto apreensão da imagem enquanto uma espontaneidade criadora, ou seja, a consciência em imagem apreende a si mesma como "uma espontaneidade que produz e conserva o objeto como imagem." (SARTRE, 1996, p. 28).

O caso é que essa ideia de uma "auto apreensão" das manifestações de consciência (a percepção, p. ex., se apreende a si mesma como passiva, ao passo que a imagem se apreende a si mesma enquanto criadora), revela que essas manifestações, em sua forma irrefletida, possuem um tipo de complexidade que precisa ser elucidado. Essa complexidade consiste no fato de que toda consciência irrefletida abarca dois tipos de relação: (1) a relação (intencional) ao objeto, e (2) a relação (imediata) a si mesma. Por um lado, as consciências põem seus objetos, colocam-nos de uma determinada forma, e a isso Sartre chama de seu ato posicional ou tético (cf. SARTRE, 1966, p. 28 [191]). Por outro lado, ao mesmo tempo em que põem seus objetos, as consciências apreendem a si mesmas, embora (e isso é extremamente importante) não ao modo de um objeto (exceto no caso da reflexão), algo que podemos chamar de sua auto relação não posicional (cf. Ibidem, p. 24 [189]) ou não tética (cf. Ibidem, p. 30 [192]). Já em seu primeiro escrito fenomenológico, o ensaio sobre A transcendência do ego (1936), Sartre esclarecera que:

\begin{abstract}
A existência da consciência é um absoluto porque a consciência é consciência dela mesma. Isto é, o tipo de existência da consciência implica ser consciência de si. E ela toma consciência de si na exata medida em que é consciência de um objeto transcendente. (SARTRE, 1966, p. $23-24$ [188]).
\end{abstract}

Isso indica que, na visão do filósofo, ao mesmo tempo em que a consciência se relaciona de modo posicional com seu objeto (colocando-o de uma determinada maneira), ela se relaciona consigo mesma de modo não posicional. Esclarecer esse modo de auto relação é fundamental para a devida compreensão da concepção sartreana da consciência.

Por um lado, o filósofo sugere que esse modo de relação a si mesma é uma característica essencial e não analisável da consciência, por exemplo quando ele afirma que "o tipo de existência da consciência é ser consciência de si" (SARTRE, 1966, p. 2324 [188]), ou que a autoconsciência é "a lei de sua existência" (Ibidem, p. 24 [188]). E o caráter primitivo, não analisável, da auto relação da consciência fica bastante claro quando Sartre recorre à seguinte comparação: "Assim como um objeto extenso está obrigado a existir segundo as três dimensões, também uma intenção, um prazer, uma dor não poderiam existir exceto como consciência imediata de si mesmos." (SARTRE, 1943, p. 20 [25]). Nessa passagem, a autoconsciência imediata é sugerida como um fato bruto a respeito da consciência de algo, um fato que não poderia ser ulteriormente explicado. 
Por outro lado, o esclarecimento filosófico da autoconsciência, no meu modo de entender, exige a tentativa de fornecer uma análise propriamente dita, do contrário, como já foi afirmado acima, pareceria subsistir um núcleo de obscuridade nessa noção de consciência de Sartre, fazendo dela uma noção inadequada. E me parece que, ao mesmo tempo em que sugere o caráter primitivo da auto relação (nas passagens citadas acima), Sartre também coloca elementos que apontam na direção de uma possível análise conceitual, uma vez que ele, como já foi colocado anteriormente, atribui algum tipo de complexidade à consciência irrefletida, complexidade que viabilizaria uma diferenciação entre certos conceitos, viabilizando uma explanação. A sugestão de que a auto relação é, simplesmente, a lei de existência da consciência sugere uma condição simples (não analisável) da consciência. Por isso indicações no sentido de uma complexidade da auto relação são importantes para viabilizar a análise conceitual. Ao afirmar que toda consciência é autoconsciência na exata medida em que é consciência de algo (cf. SARTRE, 1966, p. 24 [188]), o filósofo sugere que toda manifestação de consciência possui uma complexidade, uma vez que estão presentes duas relações: a relação ao objeto intencional e a relação a si mesma. Tal complexidade pode ser representada através da seguinte figura:

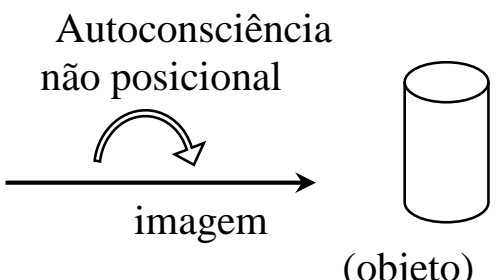

Precisamente ao mesmo tempo em que a imagem (representada pela seta preta) é um modo de consciência posicional (que, nesse caso da imagem, coloca seu objeto como um nada - seja como inexistente, seja como ausente, seja como existente em outro lugar, seja neutralizando-se - cf. SARTRE, 1996, p. 26), ela também é consciência não posicional de si mesma (representada pela seta branca), isto é, uma consciência que não coloca a si mesma como a um objeto, mas que apreende (imediatamente) a si mesma.

A simultaneidade dessas relações (a relação ao objeto e a auto relação) pode ser interpretada em termos da consciência irrefletida como sendo uma totalidade complexa, no interior da qual não há espaço para a oposição entre sujeito e objeto (típica da relação cognitiva). Fundamentalmente, é por achar que não há lugar na consciência para essa oposição que Sartre rejeita a ideia da consciência como decorrente de um sentido interno: "A consciência não é um modo particular de conhecimento, chamado sentido interno ou conhecimento de si: é a dimensão transfenomenal do sujeito." (SARTRE, 1943, p. 17 [22]). E o seu argumento para basear essa rejeição é que se a consciência irrefletida fosse uma forma de conhecimento, estaríamos diante de um regresso ao infinito. Nas palavras de Sartre:

A redução da consciência ao conhecimento, com efeito, presume introduzir na consciência a dualidade sujeito-objeto, típica do conhecimento. Mas se aceitarmos a lei da díade cognoscenteconhecido, será necessário um terceiro termo para que o cognoscente se torne por sua vez conhecido e ficaremos frente a este dilema: ou paramos em um termo qualquer da série (...) e então (...) esbarramos 
sempre com uma reflexão não consciente de si como derradeiro termo - ou então afirmamos a necessidade de regressão ao infinito (idea ideae ideae etc.), o que é absurdo. (SARTRE, 1943, p. 18-19 [23]).

Se a consciência fosse um conhecimento dos fenômenos mentais, então tal conhecimento seria distinto dos fenômenos mentais que conhece. Desse modo, se fosse o conhecimento de um dado fenômeno mental (como uma imagem, ou como uma percepção externa) que tornasse esse fenômeno consciente, então restariam duas opções: (1) essa cognição seria inconsciente, ou (2) essa cognição seria consciente. Assumir que essa cognição do fenômeno mental (tornado consciente por ela) é uma cognição inconsciente parece absurdo a Sartre ${ }^{16}$, pois significaria que a consciência surge (incompreensivelmente) do seu oposto. Mas, por outro lado, se partimos da ideia de que é uma cognição que torna consciente um dado fenômeno mental, considerar essa cognição como consciente exige uma nova cognição, que (para ser considerada consciente) exige uma terceira cognição, e assim ad infinitum.

É por isso que a consciência, isto é, cada manifestação específica de consciência (percepção, imagem, conceito etc.), não pode ser considerada um conhecimento, que está cindido de seu objeto (nesse caso um fenômeno mental), mas tem de ser considerada como uma unidade. A proposta do presente trabalho (baseada na interpretação de Gennaro) é compreender tal unidade como algo complexo. Ou seja, a consciência é uma totalidade complexa, uma totalidade que abrange simultaneamente as duas relações anteriormente discutidas: a relação posicional ao objeto e a relação não posicional a si mesma.

Para elucidar a concepção de consciência de Sartre, discutiremos algumas concepções de consciência propostas na atual filosofia da mente, concepções que se articulam a partir da distinção entre níveis de apreensão, mas que são teorias que nos auxiliam a compreender melhor a unidade da consciência que Sartre defende.

\section{Debates contemporâneos a respeito da consciência na filosofia da mente}

Entre as diversas linhas de investigação a respeito da consciência na atual filosofia da mente, uma perspectiva que tem recebido bastante atenção é aquela que investiga a consciência enquanto uma característica de estados, eventos e processos mentais, e compreende essa característica como decorrente de um monitoramento de nível superior. ${ }^{17}$ A questão básica é relativa a aquilo que diferencia um estado mental consciente de um estado mental inconsciente ${ }^{18}$, e essa linha investigação propõe que um estado mental se torna consciente quando ele é monitorado por um outro estado mental, que se dirige ao primeiro, seja este outro estado mental uma percepção (cf.

\footnotetext{
16 "Se minha consciência não fosse consciência de ser consciência de mesa, seria consciência desta mesa sem ser consciente de sê-lo, ou, se preferirmos, uma consciência ignorante de si, uma consciência inconsciente - o que é um absurdo." (SARTRE, 1943, p. 18 [23]). Nesta passagem, Sartre está se referindo a uma consciência dirigida a um objeto transcendente (uma mesa), mas, certamente, pareceria a ele absurdo que uma suposta percepção de um fenômeno mental fosse uma percepção inconsciente.

${ }^{17}$ É importante ressaltar que esse é um conceito de consciência bem distinto do conceito de Sartre. Para Sartre, todo fenômeno psíquico é consciência, ao passo que para as teorias de monitoramento de nível superior, a consciência é uma característica dos fenômenos psíquicos, mas uma característica sem a qual esses fenômenos podem existir (enquanto fenômenos psíquicos inconscientes). Cf. a nota de rodapé $\mathrm{n}^{\circ} 9$ acima.

18 "Uma questão que deve ser respondida por qualquer teoria viável sobre a consciência é: o que faz um estado mental ser um estado mental consciente? Isto é, o que transforma um estado mental inconsciente em um estado consciente?" (GENNARO, 2004, p. 1).
} 
ARMSTRONG, 1997), seja um pensamento a respeito do primeiro estado mental (cf. ROSENTHAL, 1997).

Falar em termos de um "nível superior" não significa nenhuma espécie de valoração, não significa que o estado mental que monitora seja, em qualquer sentido, "melhor" do que o estado mental que é monitorado. Significa apenas que o estado mental que monitora é "dirigido" ou é "a respeito" do estado mental que é monitorado, sendo assim um estado de "segundo nível", ou de "nível superior", em relação a ele.

Procurando explicar a consciência enquanto uma característica de estados mentais, o filósofo norte americano David Rosenthal recusa a ideia da consciência como uma percepção dos fenômenos mentais, entre outros motivos (cf. ROSENTHAL, 1997, p. 740), porque a percepção envolve a ocorrência de qualidades sensoriais, ao passo que a consciência de um estado mental não envolveria tais qualidades. ${ }^{19}$ Por isso, ele rejeita a ideia da consciência como um sentido interno, preferindo compreendê-la como decorrente da ação de um pensamento a respeito de determinados estados mentais, que em virtude desse pensamento acerca deles, se tornariam estados conscientes. Trata-se da teoria segundo a qual um estado mental se tornaria consciente no caso de ser objeto de um pensamento de nível superior (Higher Order Thought) a este mesmo estado mental. Por isso Rosenthal chama a sua teoria da consciência de "H.O.T. theory", algo como "teoria dos pensamentos de nível superior".

Uma teoria como a de Rosenthal pode ser representada por um esquema como o seguinte ${ }^{20}$, no qual vemos à esquerda a estrutura de estados de consciência que são simplesmente acerca de algo, e à direita a estrutura de estados de consciência sobre os quais realizamos uma introspecção:

\section{Estados mentais dirigidos ao mundo}

Terceira ordem

Segunda ordem

H.O.T. inconsciente (acerca de uma estado mental)

Primeira ordem

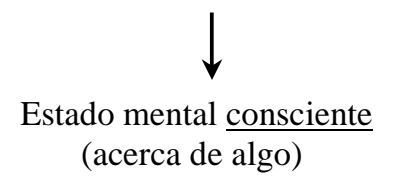

Introspecção

H.O.T. inconsciente (acerca de uma estado mental)<smiles>C1C[12CH2]1</smiles>

H.O.T. consciente (acerca de uma estado mental)

Estado mental consciente (acerca de algo)

Quando Sartre considera a consciência reflexiva como algo derivado de uma consciência irrefletida, quando ele afirma que apenas ao refletir "me vejo agir no sentido em que se diz que alguém se escura falar" (SARTRE, 1966, p. 42 [199]), e afirma que a reflexão "supõe a intervenção de uma consciência de segundo grau" (Ibidem, p. 41 [199]), as ideias do filósofo se assemelham claramente à teoria H.O.T. proposta por Rosenthal.

\footnotetext{
19 No caso de estados mentais sensorialmente neutros, como crenças, não parece haver nenhuma qualidade envolvida na consciência que se tem deles, de modo que a hipótese da consciência desses estados mentais como uma percepção se torna estranha. Mas também, no caso de estados mentais dotados de qualidade sensorial, Rosenthal enxerga dificuldades na concepção perceptual da consciência (cf. ROSENTHAL, 1997, p. 740).

${ }^{20}$ Uma figura similar a essa se encontra em Gennaro (2002, p. 297).
} 
Entretanto, essa semelhança (no caso da consciência reflexiva) abre margem para questionamentos a respeito de como a concepção sartreana da consciência poderia ser interpretada do ponto de vista da teoria H.O.T., no caso particular da consciência irrefletida, para ele a forma mais fundamental da consciência. Essa interpretação se torna problemática em virtude da unidade que Sartre atribui à consciência irrefletida, unidade que parece incompatível com a distinção de níveis da teoria H.O.T., uma unidade que, justamente, parece inviabilizar a possibilidade de um esclarecimento conceitual da consciência irrefletida. Por isso, é importante considerar agora a teoria alternativa articulada por Rocco Gennaro.

$\mathrm{Na}$ teoria de Gennaro, a "Perspectiva da Intrinsicalidade Ampla", um estado mental consciente é um complexo, formado por (a) um estado mental dirigido ao mundo e por (b) uma representação meta-psicológica (cf. GENNARO, 2002, p. 302), de modo que um estado consciente é individuado de modo amplo, isto é, abrangendo diferentes aspectos. Para Gennaro, considerar a consciência como propriedade intrínseca a certos estados mentais, não inviabiliza uma análise informativa a respeito dela, pois a propriedade intrínseca se integra a uma totalidade complexa, portanto analisável.

Gennaro defende que o pensamento que torna um outro estado mental consciente não pode ser um pensamento completamente dissociável daquele estado mental, pois esse pensamento tem que estar relacionado de um modo importante ao estado mental que ele torna consciente (cf. GENNARO, 1996, p. 16). Por essa razão, Gennaro não considera o pensamento meta-psicológico que torna consciente um determinado estado mental como um pensamento inteiramente distinto deste estado mental. O pensamento meta-psicológico, pelo contrário, está intimamente relacionado ao estado mental que ele torna consciente, por isso o estado consciente tem de ser individuado de modo amplo, isto é, abrangendo não só o estado que é tornado consciente, mas também o pensamento meta-psicológico que torna aquele estado consciente. Desse modo, apesar da relação íntima entre eles, a diferença conceitual entre o estado mental, por um lado, e o pensamento meta-psicológico, por outro lado, abre espaço para uma explicação informativa do estado consciente, na medida em que este estado é um complexo (formado por elementos intimamente relacionados).

Gennaro afirma que Rosenthal conclui falaciosamente que apenas propriedades extrínsecas de uma entidade podem ser objeto de análise e tema de uma explicação informativa. De acordo com Gennaro, do fato de uma propriedade ser intrínseca não se segue que ela não seja analisável. Ele considera difícil compreender porque uma explicação informativa da consciência (enquanto uma propriedade de estados mentais) só poderia ser construída através do recurso a um estado completamente distinto daqueles que são tornados conscientes (cf. GENNARO, 1996, p. 24), pois uma explicação informativa pode ser construída com recurso a um estado que não é completamente distinto e independente do estado mental que é tornado consciente.

Um outro aspecto positivo da teoria de Gennaro é que ela é compatível com a existência de estados mentais inconscientes (como costumam ser as teorias de nível superior), na medida em que a consciência é vista como propriedade intrínseca de certos estados mentais, não necessariamente de todos. Aliás, a temática dos estados mentais inconscientes é relevante para a interpretação da teoria de Sartre pois, em diversas passagens, ele parece rejeitar a ideia do inconsciente, que é irrestritamente aceita pelas teorias de nível superior sobre a consciência, embora existam autores que defendem a 
interpretação de que Sartre não estava necessariamente comprometido com a recusa da existência de fenômenos mentais inconscientes. ${ }^{21}$

Segundo a concepção de Gennaro, quando há um fenômeno mental consciente, dirigido ao mundo (como uma crença, um desejo ou uma percepção) não existem dois fenômenos mentais completamente distintos: um desejo, por exemplo, e um pensamento de nível superior (H.O.T.) dirigido a esse desejo; existe, na verdade, um fenômeno mental complexo, formado pelo desejo e por um pensamento meta-psicológico, que Gennaro denomina M.E.T. (Meta-Psychological Thought). Da mesma forma, quando um fenômeno mental consciente é objeto de introspecção (aquilo que Sartre denomina reflexão), não existem três fenômenos mentais independentes entre si (um H.O.T. de terceiro nível dirigido a um H.O.T. de segundo nível, que por sua vez está dirigido ao desejo), mas sim apenas dois fenômenos mentais: um complexo formado por dois pensamentos meta-psicológicos, em que um torna o outro consciente, que por sua vez torna consciente o fenômeno mental que está sendo acessado introspectivamente. Com isso, percebemos que, na teoria de Gennaro, há uma unidade entre (1) a consciência de algo e (2) a autoconsciência, ao mesmo tempo em que existe uma diferença que viabiliza uma explicação. Por isso o fenômeno mental consciente é concebido como um complexo, que articula entidades estreitamente relacionadas entre si. E é essa complexidade que, na visão de Gennaro, podemos identificar na visão de Sartre sobre a consciência irrefletida (cf. Gennaro, 2002, p. 312). A comparação entre as duas teorias pode ser representada através da seguinte figura ${ }^{22}$ :

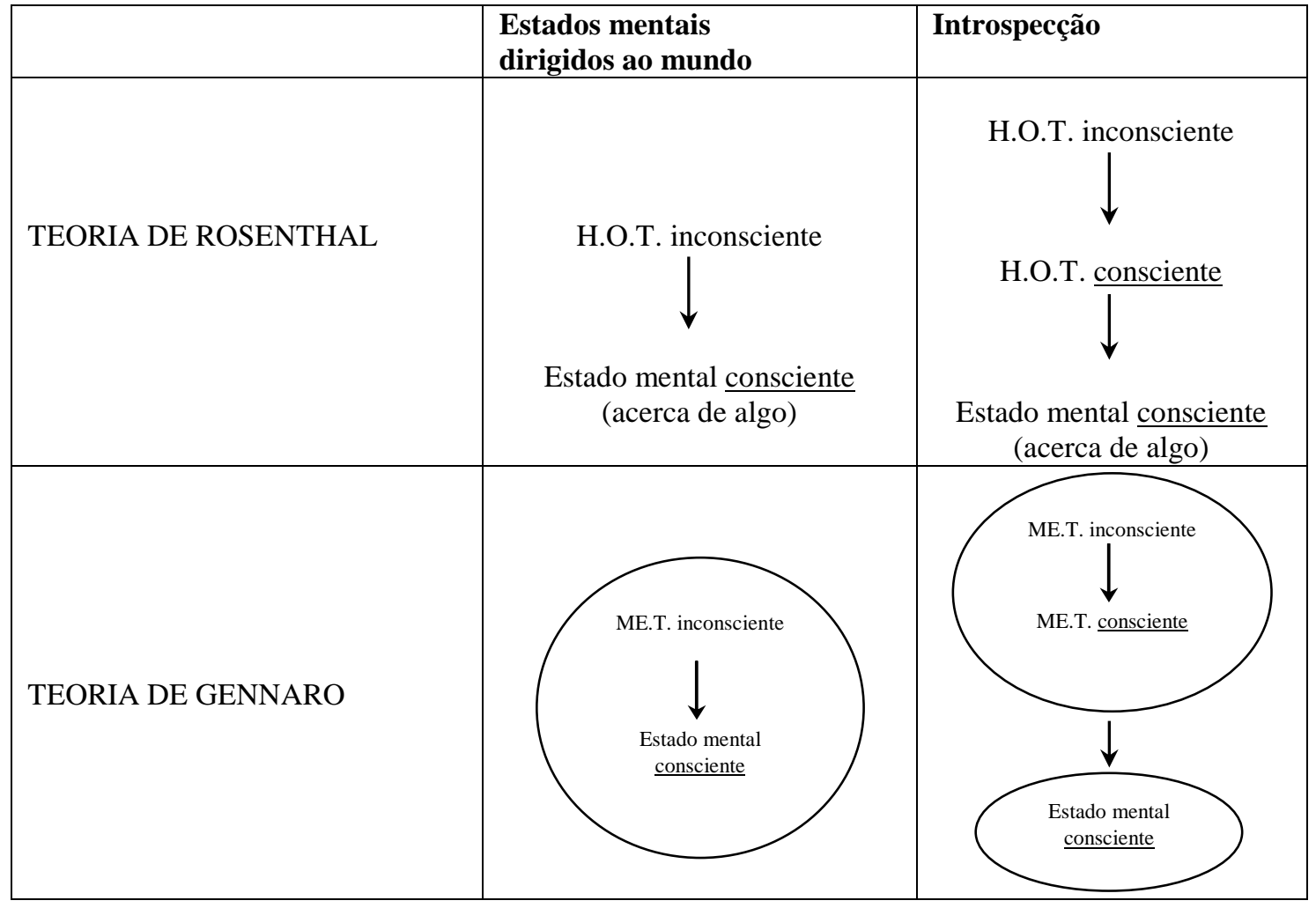

De posse desses esclarecimentos acerca da teoria de Gennaro, podemos agora examinar a concepção da irreflexividade da consciência proposta por Sartre.

\footnotetext{
${ }^{21}$ Por motivos do direcionamento temático adotado no presente artigo, não poderemos abordar aqui a complexa discussão sobre o posicionamento de Sartre sobre o inconsciente. Para maiores detalhes, cf. GENNARO, 2002, pp. 299-301.

${ }^{22}$ Uma figura similar se encontra em Gennaro (2002, p. 304).
} 


\section{Comparando as teorias de Sartre e de Gennaro}

Sem dúvida, existem diversos aspectos que aproximam a teoria de Sartre sobre a consciência das teorias de nível superior, em especial da versão de Gennaro. Como foi discutido na primeira seção acima, Sartre concebe toda consciência, na sua manifestação mais imediata, isto é, quando não há reflexão, como autoconsciência. Toda consciência irrefletida se lança completamente rumo ao seu objeto, mas é, também, consciência de si "na exata medida em que é consciência de um objeto transcendente." (SARTRE, 1966, p. 24 [188], grifado no original).

É bem verdade que muito do que escreve Sartre a esse respeito parece ter como meta provar que cada manifestação de consciência (p. ex. uma crença, um desejo, uma imagem, etc. - cf. SARTRE, 1996, p. 13) é algo uno, sem complexidade interna. Um bom exemplo disso é a seguinte passagem, já citada parcialmente acima:

Esta consciência (de ${ }^{23}$ si não deve ser considerada uma nova
consciência, mas o único modo de existência possível para uma
consciência de alguma coisa. ${ }^{24}$ Assim como um objeto extenso está
obrigado a existir segundo as três dimensões, também uma intenção,
um prazer, uma dor não poderiam existir exceto como consciência
imediata de si mesmos. (SARTRE, 1943, p. 20 [25], grifado no
original).

A afirmação de que a autoconsciência não posicional não é "uma nova consciência" pode ser interpretada no sentido de que não há uma complexidade, de que se trata de um único fenômeno mental. E Sartre chega, inclusive, a explicar a noção de "não posicional" em termos de que a autoconsciência irrefletida "identifica-se com a consciência da qual é consciência" (Ibidem, p. 20 [25], grifo meu). E afirmar uma identidade entre essas consciências sugere uma unidade que torna a consciência irrefletida opaca para qualquer explicação.

Entretanto, penso ser possível articular uma outra interpretação de sua teoria, uma interpretação que torne essa teoria mais plausível, pois a ausência de complexidade interna parece inviabilizar uma explicação (propriamente dita) da consciência, de modo que a aceitação dessa complexidade me parece fortalecer a teoria de Sartre. É importante lembrar que, em certas passagens, Sartre se refere aos episódios de consciência (consciência perceptiva, consciência em imagem, consciência de um conceito) como "organizações sintéticas" (cf. p. ex. SARTRE, 1996, p. 19), o que mostra que sua teoria é, sim, compatível com a ideia das manifestações de consciência enquanto sistemas complexos. Se cada episódio particular de consciência é uma "organização sintética", como diz Sartre a respeito da imagem, isso significa que há uma síntese de elementos diferentes, que se organizam de um determinado modo. Dessa maneira, cada episódio particular de consciência tem de ser uma multiplicidade articulada de elementos distintos.

\footnotetext{
23 Sartre coloca a preposição "de" entre parênteses para indicar que ela está no texto apenas por necessidade gramatical, pois o uso da partícula não deve indicar a dualidade entre sujeito e objeto.

24 Sobre a consciência irrefletida, ele afirma: "ela é puramente e simplesmente consciência de ser consciência deste objeto, esta é a lei de sua existência." (SARTRE, 1966, p. 24 [188], grifo meu).
} 
De fato, parece ser mais inteligível conceber os episódios de consciência irrefletida como entidades complexas (segundo o modelo da teoria de Gennaro), pois tal complexidade permite uma explicação conceitual da consciência irrefletida, sem que sejam necessárias expressões metafóricas, é o caso da menção às dimensões espaciais de um objeto físico na citação acima (SARTRE, 1943, p. 20 [25]).

Sendo assim, quando Sartre afirma, por exemplo, que a autoconsciência constitutiva de uma consciência irrefletida "não é uma nova consciência" (Ibidem, p. 20 [25]), ou afirma que essa autoconsciência "identifica-se com a consciência da qual é consciência" (Ibidem, p. 20 [25]), essas afirmações podem ser interpretadas no sentido de que essa autoconsciência (não posicional) é um componente indispensável de uma entidade complexa. O ponto decisivo aqui é que essa entidade (de acordo com tal interpretação) pode, em princípio, ser decomposta, pelo simples fato de que ela é um complexo. Mas caso ela seja, efetivamente, decomposta ela imediatamente deixa de merecer a designação de "consciência", da mesma forma que uma porção de cacos de vidro espalhados sobre o piso de uma cozinha não mereceria ser designada como um "copo".

Do mesmo modo, a afirmação de que uma consciência é "um ser indivisível" (SARTRE, 1943, p. 21 [26]) pode ser interpretada no sentido de que, durante o tempo no qual ele existe efetivamente, tal episódio de consciência não pode ser decomposto, pois se seus elementos constituintes forem efetivamente dissociados, então o episódio de consciência deixa de existir. De acordo com a presente interpretação, essa indivisibilidade da consciência defendida por Sartre não deve ser compreendida como uma impossibilidade conceitual de discernir os elementos constituintes da "organização sintética" que é cada episódio de consciência irrefletida. Essa indivisibilidade deve, na verdade, ser compreendida no sentido de que caso os elementos daquela organização sintética sejam efetivamente dissociados, então ele deixa de existir.

Por outro lado, da mesma maneira que esclarece o modo de existência da consciência irrefletida, a teoria de Gennaro (por ser uma forma de teoria de nível superior) se mostra adequada para esclarecer o caso da consciência reflexiva, e se oferece como referencial para se esclarecer a concepção de Sartre a esse respeito. Na medida em que "a reflexão supõe a intervenção de uma consciência de segundo grau" (Sartre, 1966, p. 41 [199]), é bastante intuitivo, nos marcos dessa teoria, interpreta-la no sentido de um complexo (nos termos de Gennaro, um complexo de dois pensamentos meta-psicológicos) que se dirige a um estado de consciência (que está sendo refletido). $\mathrm{Na}$ terminologia de Sartre, teríamos uma consciência reflexionante (que se autorelaciona de modo não posicional) que se dirige a uma consciência refletida, que é consciência posicional de algo transcendente. A similaridade entre as duas teorias pode ser representada através da seguinte figura ${ }^{25}$ :

${ }^{25}$ Uma figura similar se encontra em Gennaro (2002, p. 309). 


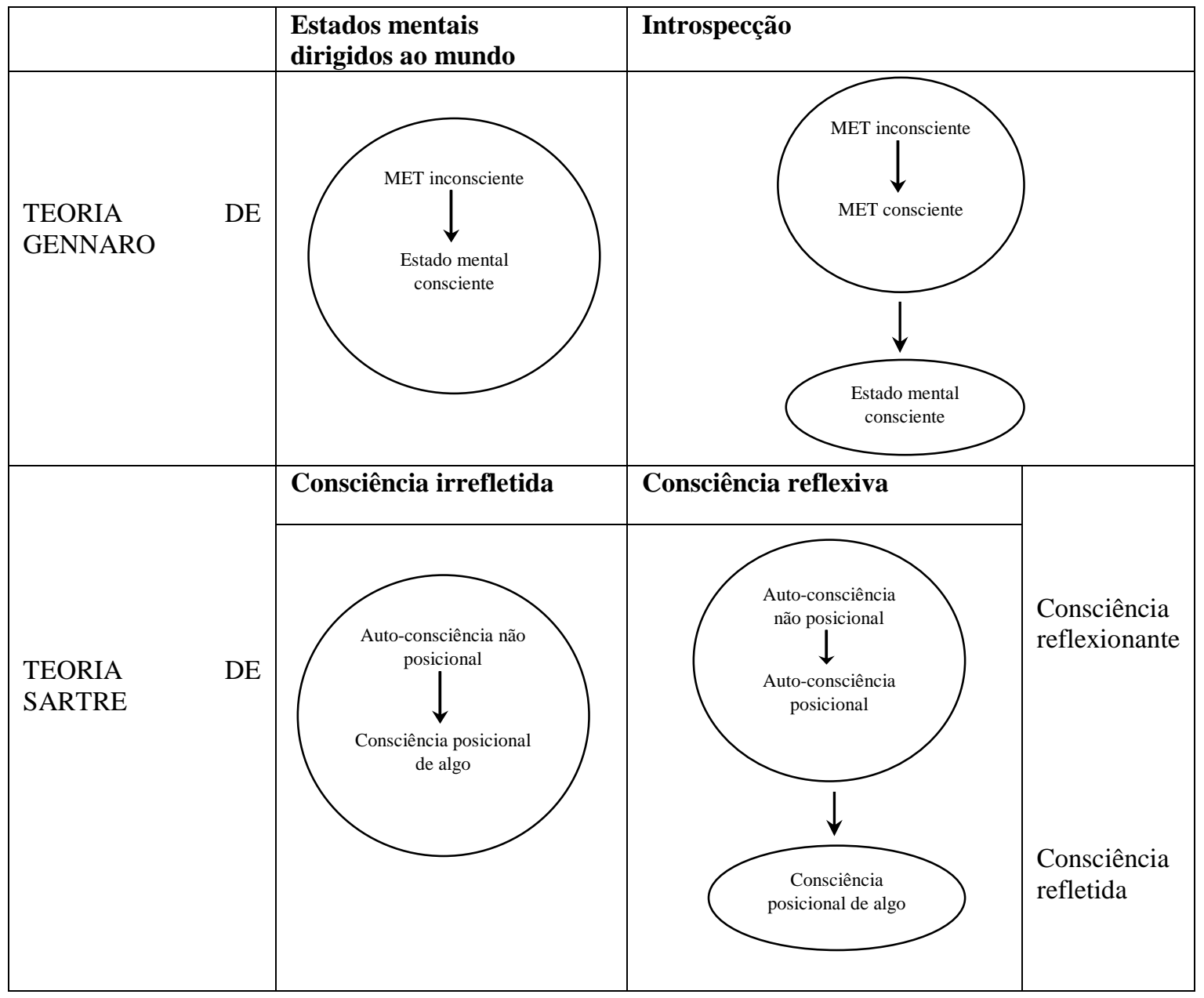

\section{Considerações finais}

A visão segundo a qual toda consciência de algo se relaciona consigo mesma (apreende a si mesma) de modo não reflexivo, é uma visão bastante plausível, pois se coaduna com o fato de que a reflexão (o direcionamento da atenção para os próprios estados mentais) é um fenômeno relativamente raro em nossa vida psicológica, de modo que a maioria esmagadora de nossos estados conscientes não poderia depender da reflexão. Na maior parte de nossa vida, o foco de nossa atenção está voltado para além de nós mesmos, de maneira que não é razoável supor que toda consciência de estados mentais decorra da reflexão. Esse é um motivo pelo qual a concepção de Sartre sobre a consciência me parece bastante atraente, pois ela dá conta do lugar secundário da reflexão em nossas experiências conscientes.

Para compreender isso é importante ter em vista a diferença entre estados mentais conscientes, por um lado, e aquilo que Rosenthal denomina "introspecção", por outro lado, pois a introspecção é um fenômeno mais complexo e, como já foi colocado acima, não tão frequente em nossa existência psicológica. A meta das teorias de monitoramento de segunda ordem (como as de Rosenthal e Gennaro) é elucidar a consciência como uma propriedade de estados mentais, mesmo nos casos mais simples 
(e mais frequentes) nos quais não há introspecção. Sobre a diferença entre consciência introspectiva e não introspectiva, Rosenthal esclarece:

Quando prestamos atenção deliberadamente ao estado mental no qual nos encontramos, estamos introspectivamente conscientes desse estado. Isso é diferente do modo como estados mentais são conscientes quando não estamos deliberadamente focando nossa atenção sobre eles. Introspecção é consciência atenta e deliberada de nossos estados mentais. É algo relativamente raro, e é algo mais elaborado do que a maneira na qual estados mentais são ordinariamente conscientes. Quando realizamos introspecção, não estamos apenas cientes [aware] do estado mental em que estamos, nós estamos cientes de estarmos cientes dele. A diferença entre consciência introspectiva e não introspectiva emerge vividamente se notarmos que, quando um estado é consciente de modo não introspectivo, ele normalmente tem o potencial de ser um objeto de introspecção. (Rosenthal, 1997, p. 730).

Como vimos, a visão de Rosenthal é que a consciência de um estado mental (em seu modo não introspectivo) decorre de seu monitoramento por um pensamento acerca dele, ao passo que a visão de Gennaro é que essa consciência (sem introspecção) decorre de um pensamento meta-psicológico estreitamente conjugado ao estado mental que ele torna consciente. No caso da teoria de Rosenthal, temos o monitoramento de um estado mental por um segundo estado mental (um pensamento), enquanto no caso da teoria de Gennaro temos, propriamente, algum tipo de auto relação, pois o pensamento meta-psicológico não é totalmente distinto do estado mental que ele torna consciente, já que tal pensamento faz parte de um mesmo todo, junto com esse estado mental. É por isso que Gennaro entende que a visão de Sartre sobre a consciência era bastante similar à sua própria teoria, pois tanto a Perspectiva da Intrinsicalidade Ampla quanto a teoria de Sartre compartilham a visão de que toda consciência de algo é autoconsciência (GENNARO, 2002, p. 293).

Mas se tanto a visão de Sartre quanto a de Gennaro dão conta do caráter não reflexivo da autoconsciência, a visão de Gennaro tem a virtude de articular uma explicação conceitual dessa forma de auto relação (a autoconsciência), enquanto o pensamento de Sartre, no meu modo de entender, se deixa envolver em uma certa obscuridade, uma vez que, em diversas passagens, sugere que a auto relação de todo episódio de consciência é algo como um fato bruto, refratário a uma explicação. Por outro lado, vimos que algumas colocações de Sartre dão margem para a interpretação de que sua teoria é compatível com algum tipo de explicação conceitual, de modo que a noção de consciência de Sartre pode ser entendida (a exemplo da teoria de Gennaro) como dizendo respeito a algum tipo de totalidade complexa.

Sendo assim, a perspectiva da intrinsicalidade ampla proposta por Gennaro, e a interpretação do conceito sartreano de consciência construída a partir dessa perspectiva, se mostram como concepções muito proveitosas para se compreender o pensamento de Sartre e, além disso, para se compreender o próprio fenômeno da consciência.

\section{Referências}

Armstrong. A. "What is Consciousness?". In: BLOCK, N.; FLANAGAN, O.; GÜZELDERE, G. (Orgs.). The Nature of Consciousness: philosophical debates. Cambridge (Massachusetts): MIT Press, pp. 721-728, 1997. 
ASTRUC, A.; CONTAT, M. Sartre par lui même. Dir.: Alexandre Astruc; Michel Contat: L'institut national de l'audiovisuel, 1976. (tempo: 3h, 09', 17').

BEAUVOIR, S. A força da idade. Rio de Janeiro: Nova Fronteira, 1984.

BEAUVOIR, S.; SARTRE, J.-P. "Entrevistas com Jean-Paul Sartre (Agosto - Setembro de 1974)" In: Beauvoir, S. A cerimônia do adeus. Rio de Janeiro: Nova Fronteira, 1982, pp. 175604.

BIERI, P. "Was macht Bewusstsein zu einem Rätsel?" In: METZINGER, T. (Org.) Bewusstsein: Beiträge aus der Gegenwartsphilosophie. 3. ed. Paderborn, Munique, Viena, Zurique: Schöningh, 1996.

BRENTANO, F. Psychologie vom empirischen Standpunkt. 2. ed. Leipzig: Meiner, 1924. [Original de 1874].

. Psychology from an empirical standpoint. London: Routledge \& Kegan Paul, 1995.

COHEN-SOLAL, A. Sartre - 1905-1980. Porto Alegre; São Paulo: LPM Editores, 1986.

. Sartre. Porto Alegre: L\&PM, 2007.

CHURCHLAND, P. M. Matéria e Consciência: Uma introdução contemporânea à Filosofia da Mente. São Paulo: UNESP, 2004.

COSTA, C. Filosofia da mente. Rio de Janeiro: Jorge Zahar, 2005.

GENNARO, R. J. Consciousness and Selfconsciousness: a Defense of the Higher Order Thought Theory of Consciousness. Amsterdam/Philadelphia: John Benjamins Publishing, 1996.

"Jean-Paul Sartre and the HOT Theory of Consciousness". Canadian Journal of Philosophy, v. 32, n. 3, p. 293-330, setember 2002.

Higher-Order Thories of Consciousness: An anthology. Amsterdam; Philadelphia: John Benjamins Publishing Company, 2004.

GÜZELDERE, G. "Introduction - Many Faces of Consciousness: A Field Guide" In: BLOCK, N.; FLANAGAN, O.; GÜZELDERE, G. (Orgs.). The Nature of Consciousness: philosophical debates. Cambridge (Massachusetts): MIT Press, p. 1-67, 1997

HEIL, J. Filosofia da mente: uma introdução contemporânea. Lisboa: Instituto Piaget, 2001.

HUSSERL, E. Logische Untersuchungen II: Untersuchungen zur Phanomenologie und Theorie der Erkenntnis. Den Haag: Martinus Nijhoff, 1984. (Husserliana XIX/1).

. Investigações Lógicas: Segundo volume, parte I: Investigações para a Fenomenologia e Teoria do Conhecimento. Trad. de Pedro M. S. Alves. Rio de Janeiro: Forense Universitária, 2012.

MASLIN, K. T. Introdução à filosofia da mente. 2. ed. Porto Alegre: Artmed, 2009.

ROSENTHAL, D. "A Theory of Consciousness". In: BLOCK, N.; FLANAGAN, O.; GÜZELDERE, G. (Orgs.). The Nature of Consciousness: philosophical debates. Cambridge (Massachusetts): MIT Press, 1997, p. 729-753.

SARTRE, J.-P. L'être et le neánt: essai d'ontologie phénoménologique. Paris: Gallimard, 1943.

Vrin, 1966.

La transcendece de l'Ego - esquisse d'une description phénoménologique. Paris:

As Palavras. São Paulo: Difusão Européia do Livro, 1967.

"A imaginação". In:

O existencialismo é um humanismo; A imaginação;

questão de método. São Paulo: Abril Cultural, pp. 35-107, 1978. (Coleção Os Pensadores). [orig. 1936].

O imaginário: psicologia fenomenológica da imaginação. São Paulo: Editora Ática, 1996. [orig. 1940].

. O ser e o nada: ensaio de ontologia fenomenológica. Petrópolis: Vozes, 1997.

"Tradução do texto de Jean-Paul Sartre: une idée foundamentale de la phénoménologie

de Husserl: L’intentionalité", Veredas Favip, Caruaru, v. 2, n. 1, jan-jun. 2005, p. 102-107.

"A transcendência do ego - esboço de uma descrição fenomenológica". Cadernos

Espinosanos, XXII, 2010a, p. 183-228.

Esboço para uma teoria das emoções. Porto Alegre: L\&PM, $2010 \mathrm{~b}$.

THODY, P. Sartre: uma introdução biográfica. Rio de Janeiro: Bloch Editores, 1974. 
